\title{
The Measurement of Ocean Scientific and Technological Progress Contribution in China
}

\author{
Kedong Yin $^{1} \&$ Hengda Zhang ${ }^{1}$ \\ ${ }^{1}$ School of Economics, Ocean University of China, Qingdao, China \\ Correspondence: Kedong Yin, School of Economics, Ocean University of China, 238 Song Ling Road, Lao Shan \\ Qu, Qingdao 266100, China. Tel: 86-0532-6678-2085. E-mail: yinkedong537@gmail.com
}

Received: March 15, 2012

Accepted: June 26, $2012 \quad$ Online Published: July 11, 2012

doi:10.5539/ijef.v4n8p126

URL: http://dx.doi.org/10.5539/ijef.v4n8p126

\begin{abstract}
Marine science and technology, which supports the development of marine economy, has entered the frontier of the international science and technology the effect is becoming increasingly evident. From the perspective of the role of marine S\&T on the development of marine economy, this paper builds measurement model basing on C-D production function and Solow residual method to calculate the contribution rate of marine scientific and technological progress. It turns out that marine scientific and technological progress contributes approximately $23.35 \%$ to the entire marine economy during 2001 and 2010. This paper also analyzes the factors influencing the contribution rate marine scientific and technological progress, and then provides several policy proposals.
\end{abstract}

Keywords: ocean scientific and technological progress, contribution, C-D production function, solow residual method

\section{Background of the Study}

"Countries outstanding in the world first sing in the oceans, those who decline first lose in marine." Marine science and technology is increasingly becoming an important content of the development of national marine programs. Marine science and technology has entered the forefront of global technology competition and seizing the "high ground" of marine science and technology has become the main characteristic of struggle for the modern maritime rights and interests. All technology used for marine development of is almost capital-intensive and knowledge-intensive high and new technology. Some maritime powers of the world, such as the United States, Japan, Britain and France, attach great importance to the development of marine high-tech and investing a lot of money and human resources in marine high-tech. Progress of marine science and technology contributes more than $50 \%$ to the development of marine economy.

China pays more and more attention to the marine science and technology. China released the "China's Ocean Agenda of 21th Century" and Blue Book of "Marine Technology Policy", formulated "Outline of Implementation of National Revitalizing the Ocean through Science and Technology of Ninth Five-Year Program and 2010" and "National Outline of Marine Economy Development Plan", promulgated and implemented "Outline of National Marine Science and Technology Development Plan of Eleventh Five-Year" and "Outline of National Revitalizing the Ocean through Science and Technology Plan (2008-2015). China brings marine research into the national "907 Program" and "863 Program", increases the input of marine science and technology, emphasizes talent training on marine science and technology, and intensifies efforts to technology transformation of marine science and technology, comprehensive strength of the marine science and technology continuing to improve. Driven strongly by marine science and technology, the output of China's major marine industries increased to 3.8439 trillion RMB in 2010 from 0.1707 trillion RMB in 1994, an increase of more than 20 times. In 2010, gross marine product shares $9.7 \%$ of GDP and the marine economy has an increasingly prominent position in the national economy.

Although China's marine science and technology has made a great progress and the marine economy has got a considerable development, the contribution rate of the marine scientific and technological progress on the development of marine economy is still relatively low, still with a big gap with the world's maritime powers. Therefore, the research on contribution of marine science and technology meets the requirements of national strategy of strengthening the country through the ocean at present and has obvious practical significance for improving contribution rate of the marine scientific and technological progress, developing of marine economy 
and building a maritime power.

\subsection{Literature Review of Contribution Rate of Scientific and Technological Progress}

Abroad, Tinbergen, a Dutch economist, (1942) first defined the problem of total factor productivity, listed the time trend with capital and labor inputs and constructed one of the first formulas of neoclassical theory. Davis (1954) first clearly proposed the connotation of total factor productivity and pointed out that total factor productivity should be estimated according to all input elements, and therefore known as the founder of total factor productivity. Subsequently, Fabulikan and Kendrick made a further supplement for the meaning of productivity.

Solow (1957) took technological progress into the production function, constructed the relationship among output growth rate, the input factors (capital, labor) growth rate and total factor productivity growth rate in quantity. On the Solow model, Dennison further depictured decomposition of the factors that affect total factor productivity as improvement of the allocation of resources, economies of scale and the advancement of knowledge, and used data of U.S. to show that the advancement of knowledge to explain about $2 / 3$ of the contribution of technological progress on economic growth. In 1970s, Jorgenson, a U.S. economist, proposed beyond the logarithmic total production function, improve the estimation of technical progress to a new level. Griliches (1986) studied the data of about 1000 American largest manufacturing enterprises during 1957 to 1977 , and the results showed that investment in science and technology played an important role in improving productivity, of which investment in R \& D played a particularly important role. Coe and Helpman (1995) studied the relationship of investment in science and technology and total factor productivity with a sample of 22 countries.

In the domestic, the quantitative study of the contribution rate of technological progress in China began in the early 1980s. Shi Qingqi, Qinbao Ting (1985), proposed the calculation model of the contribution rate of industrial structure and technological progress, introduced a variety of parameters to measure the correspondence relationship between the input and output in the national economy and the scientific and technological progress. According to the intrinsic relationship between the scientific and technological progress and efficiency, Feng Yingjun and Li Chenghong $(1992,1999)$, proposed equal efficiency surface method which is used to calculate contribution rate of technological progress. According to different characteristics of the logging industry and the business forestry, Huang Heyu and Li Zhiyong (1995), using production function method and the analytic hierarchy process analysis respectively, measured the contribution rate of technological progress and conversion rate of forestry achievements. Zhao Dawei (1998) using the method of Jiang Zhaohua, estimated the contribution rate of the industrial economy of China from 1953 to 1993. Wu Wenjiang (1999) proposed the possibility of special rate of technological progress with DEA. Wang Tianying (2003) measured the contribution rate of national science and technology from 1981 to 2002 based on the hypothesis of loosening constant returns to scale. Li Xieyi and Guo Yajun(2007) measured the contribution rate of scientific and technological progress of Shanxi Province. Wang Xiongjun Guo Xiaoqun (2008) measured the contribution rate of scientific and technological progress of Jiangxi Province on the basis of considering the cumulative effect and the lag effect of the scientific and technological progress. Yu Jie, Liu Runsheng and Cao Yan (2009) make a quantitative analysis of the contribution rate of China's scientific and technological progress based on the DEA method, using non-parametric DEA-the Malmquist index approach. Zhou Shaosen and Hu Delong (2010) proposed the scientific and technological progress is reflected by five major factors such as human capital, research and development, economic benefits of energy per unit, adjustment of the industrial structure, and the degree of market and on this base made an empirical analysis of the contribution of each factor on China' economic growth from 1980 to 2007.

\subsection{Literature Review of Contribution Rate of Marine Scientific and Technological Progress}

There are many researches on contribution rate of marine scientific and technological progress at present at home and abroad, but there are few specific researches on marine areas which are scattered among domestic scholars' research on the marine economy. Liu Xisong and Ye Xiangli (2004) mentioned that the current contribution rate of scientific and technological progress on the marine economy has been more than $50 \%$ in developed countries. Ye Xiangdong (2006) pointed out the contribution rate of marine technological progress has reached more than $80 \%$ in the United States, Japan, Britain, France and some other countries and the contribution rate of marine technological progress has reached 45\% in China. Ma Zhilong and Zhang Li (2007) pointed out that technological innovation has contributed up to $80 \%$ or so in the development of marine economy in developed countries, while it is only $30 \%$ in China. Sun Linjie and Wu Zhuoliang (2008) pointed out that there is a gap between marine economic development in China and that of developed countries and contribution 
rate of marine science and technology was 3.4\%, which is below the level of $14 \%-17 \%$ in developed countries of marine economy, less the world's average of 5\%. Liu Dahai and Li Long (2008), based on "Solow growth rate equation method", measured the contribution rate of marine scientific and technological progress in the period of China's Tenth Five-Year, and the average of the contribution rate of marine scientific and technological progress in the period of China's Tenth Five-Year is 35\%. Qiao Junguo (2010) pointed out that China's marine scientific and technological progress leads new marine industries and promotes optimization of marine industrial structure.

In summary, in the existing research on contribution rate of scientific and technological progress, there are many different ways to measure contribution rate of scientific and technological progress with advantages and disadvantages, of which the most commonly used in terrestrial studies is the Solow balance method. There are few researches on contribution rate of marine scientific and technological progress and there are significant differences among the conclusions. Most researches did not give the data source, and calculation method. Therefore, using reasonable methods to get the contribution rate of marine scientific and technological progress and the correctly assessing of the contribution of marine science and technology is very tight, with very significant meaning and value.

\section{Data and Methodology}

\subsection{The Collection and Processing of Data}

\subsubsection{Statistics Caliber Choice for Each Index}

Economic indexes such as output, capital amount, and the amount of labor must have the unified regulations when measuring the influence of marine science and technology progress on ocean economic growth are being measured, otherwise, it will turn out different results, lack of comparability.

(1) Determination of the output. At present economic development scale, speed and level are mostly reflected by GDP. Therefore, the total output of marine production is taken as the substitution index in this article.

(2) Determination of labor capacity. The caliber of related ocean employment is adopted in course of the study.

(3) Determination of capital input. Capital inputs are obtained from the result that proportion of the ocean GDP in GDP is multiplied by the total investment amount for fixed assets.

\subsubsection{Data Collection and Processing}

There is hysteresis quality in the role of science and technology advance during economic growth, therefore a cycle measurement is more reasonable for contribution rate of marine science and technology advance. Due to inconformity of marine economic data statistics caliber, the ocean GDP, ocean industries added value, marine capital investment, etc. are subject to base determination processing before report, and the basis point is the year of 2001 under the condition that the calculated result is not influenced. Among them, fixed base index of the marine industry added value is converted from GDP based on the basis point of 1978 in China statistical yearbook, fixed assets investment convert index is from the fixed assets index based on the basis point of 1991 in China statistical yearbook.

\subsection{Determination of the Model Parameters for Marine Science and Technology Progress}

\subsubsection{Assumption of the Solow Residual Method in the Ocean Output}

Through Solow's strict mathematical derivation for the production function of output growth type, "growth residual value" is called for growth produced by other non-input elements besides material input elements in output growth. The residual value contains the effect of variable factors such as technology innovation, human capital accumulation, an increase in knowledge, learning effect and structure change. It is no longer narrow sense of technology innovation.

The general form of C-D production function is $Y_{t}=A_{0} e^{r t} K_{t}{ }^{\alpha} L_{t}{ }^{\beta}$, among them, $Y, K, L$ present marine output, the ocean capital inputs, labor inputs respectively, $\alpha, \beta$ are marine capital, labor output elasticity respectively, $A_{0}$ is a constant, indicating technology level of the base year, $r$ is also a constant, showing the growth rate in marine science and technology progress, $t$ signifies time, $A_{0} e^{r t}$ means $t$ years' comprehensive marine science and technology level.

Take logarithms for both sides of the marine production function, $\ln Y_{t}=\ln A_{0}+r t+\alpha \ln K_{t}+\beta \ln L_{t}$ can be obtained, and then make derivation for time $t$ on the both sides of the above equation at the same time, $y=r+\alpha k+\beta l$ is obtained. 
If $\alpha+\beta>1$, it means increasing scale returns, while $\alpha+\beta<1$ means diminishing scale returns, $\alpha+\beta=1$ says the unchanged scale returns, in the measure of article, unchanged scale return is used.

Neutral technology progress refers to the unchanged shape of yield curve when there is existing technology progress, namely the technology progress doesn't cause the changes of capital and labor investment proportion. The technology progresses are further classified through the comparison of marginal capital output rate and marginal labor output rate in the production function based on derivation for time. Among them, the hicks neutral shows that before and after the progress of science and technology, $\frac{\partial Y}{\partial K} / \frac{\partial Y}{\partial L}$ (the marginal production ratio of the capital and labor) is unchanged when the ratio $K / L$ of production elements capital and Labor remains the same, namely the marginal substitution rate does not change, but the relationship between input and output.

\subsubsection{Determination of Model Parameters for Contribution Rate of Marine Science and Technology Progress}

This paper adopts 1985-1991 years of major ocean industries, measurement data. To explain, because 2000 years ago major ocean industries without the added value of the data, so, this article with the major ocean industries instead of the earnings of the data, labor, capital input data comply with the provisions of the above, specific data see table 1 .

Table 1. Related data of national major ocean industries 1985-1991

\begin{tabular}{cccc}
\hline Year & $\begin{array}{c}\text { Gross Output Value of Major } \\
\text { Marine Industries (100 million } \\
\text { Yuan) }\end{array}$ & $\begin{array}{c}\text { Employed Personnel in the Major Marine } \\
\text { Industries (10000 persons) }\end{array}$ & $\begin{array}{c}\text { Investment in fixed assets of Marine } \\
\text { Industries (10 thousand Yuan) }\end{array}$ \\
\hline 1985 & 147.60 & 97.07 & 34.12 \\
1986 & 212.79 & 100.00 & 52.96 \\
1987 & 249.24 & 107.84 & 101.42 \\
1988 & 279.52 & 111.47 & 90.68 \\
1989 & 240.17 & 105.43 & 76.78 \\
1990 & 268.75 & 117.58 & 101.83 \\
1991 & 311.01 & 127.68 & 135.21 \\
\hline
\end{tabular}

Data sources: the 1986-1992 China ocean statistical yearbook

Due to the short time sequence, different forms of c-d production function are separately applied to measure and compare $\alpha, \beta$ in this paper:

(1) Application of $Y=A K^{\alpha} L^{\beta}$ for the regression

Take logarithms on both sides of the above model to get $\ln Y=\ln A+\alpha \ln K+\beta \ln L$, after logarithm process for the above data respectively make least-squares regression, homoscedastic as well as the related adjustment the to get the following results :

$$
\begin{gathered}
\qquad \begin{aligned}
\ln Y=4.8535+0.6033 \ln K-0.4282 \quad \ln L \\
(3.8939)(5.4398)(-1.1732)
\end{aligned} \\
\text { Adjusted } \mathrm{R}^{2}=0.9814, F=159.0000, D . W .=3.3822
\end{gathered}
$$

By the above results that the output elasticity coefficient of labor for negative, do not accord with the actual economic significance, and at the same time, labor output elasticity coefficient and failed to pass a parameter of the significant inspection, equation there since the related phenomenon in itself. Therefore, the above equation and can't correctly reflect the rule of marine economic growth.

(2) Application of $Y=A_{0} e^{r t} K^{\alpha} L^{\beta}$ for the regression

Based on c-d production function, time is added to $Y=A_{0} e^{r t} K^{\alpha} L^{\beta}$, among them, $r$ says the average speed of technology progress. After the logarithm process and regression, the results are as follows:

$$
\begin{aligned}
\ln Y= & 4.7995+0.0168 t+0.5180 \ln K-0.3545 \ln L \\
& (3.6726)(0.7026)(3.3924)(-0.9364)
\end{aligned}
$$




$$
\text { Adjusted } \mathrm{R}^{2}=0.9910, F=110.4354
$$

Compared with the results (1), the equation goodness-of-fit improves, but labor output elasticity coefficient is negative, the coefficient also fails to pass significant inspection. In general, the average growth speed of technology progress should be positive, namely technology progress is continuous, but the regression results do not support such conclusion, therefor it is also not reliable.

(3) Application of $\frac{Y}{L}=A\left(\frac{K}{L}\right)^{\alpha}$ for the regression

Considering the relatively short time series, the unusual results of former two model form regression are probably because of too many estimated parameters. A new form $\frac{Y}{L}=A\left(\frac{K}{L}\right)^{\alpha}$ can be gained from deformation for the model, which can save degree of freedom, at the same time include $\alpha+\beta=1$, that is the assumption that the scale remuneration is unchanged. By regression, results are as shown in table 2 :

$$
\ln \frac{Y}{L}=0.8959+0.3566 \ln \frac{K}{L}
$$

$$
\text { (32.4054) (4.3002) }
$$

$$
\text { Adjusted } \mathrm{R}^{2}=0.7872, F=18.4919, \quad D . W .=2.3898
$$

The results show that, for the marine economy, computing of its capital and labor output elasticity are subject to time series, so only choosing the model form that save the best degree of freedom can obtain the best regression results. Compare the regression results of the three kinds of models, only the form of $\frac{Y}{L}=A\left(\frac{K}{L}\right)^{\alpha}$ has the best regression results, all the parameters pass the significant inspection and economic significance test, capital output elasticity is 0.357 , labor output elasticity is 0.643 , the conclusion is very close to the reference value ( $\alpha=0.35, \beta=0.65$ ) given by the state planning commission, statistical bureau. Therefore, measurements on the contribution rate of ocean scientific and technological progress below is calculated on the basis of $\alpha=0.357$ and $\beta=0.643$.

Table 2. the regression result of $\frac{Y}{L}=A\left(\frac{K}{L}\right)^{\alpha}$

\begin{tabular}{lllll}
\hline Variable & Coefficient & Std. Error & t-Statistic & Prob. \\
\hline C & 0.895890 & 0.027646 & 32.40543 & 0.0000 \\
KK & 0.356613 & 0.082929 & 4.300218 & 0.0077 \\
\hline \multicolumn{4}{c}{ Weighted Statistics } \\
\hline R-squared & 0.787160 & Mean dependent var & 0.801307 \\
Adjusted R-squared & 0.744593 & S.D. dependent var & 0.409726 \\
S.E. of regression & 0.058322 & Akaike info criterion & -2.610715 \\
Sum squared resid & 0.017007 & Schwarz criterion & -2.626169 \\
Log likelihood & 11.13750 & F-statistic & 18.49188 \\
Durbin-Watson stat & 2.194079 & Prob(F-statistic) & 0.007714 \\
\hline & \multicolumn{3}{c}{ Unweighted Statistics } & 0.781652 \\
\hline R-squared & 0.814188 & Mean dependent var & 0.168244 \\
Adjusted R-squared & 0.777025 & S.D. dependent var & 0.031558 \\
S.E. of regression & 0.079445 & Sum squared resid & \\
Durbin-Watson stat & 2.389769 & & \\
\hline
\end{tabular}

\section{Measurement on Contribution Rate of Marine Science and Technology Progress Based on the Method of Solow Residual Method}

\subsection{Measuring Process of Contribution Rate of Marine Science and Technology Progress}

Marine production function can be expressed as $Y_{t}=A_{t} f(K, L)$, among them $Y$ for marine GDP, $t$ as the time variable, $A_{t}$ says marine science and technology progress coefficient.

After series transformation of the function, make $t$ the total differential and divided by $Y$ : 


$$
\frac{\frac{d Y_{t}}{d_{t}}}{Y}=\frac{\frac{d A}{d_{t}}}{A}+\frac{\partial f}{\partial K} \frac{\frac{d K}{d_{t}}}{Y}+\frac{\partial f}{\partial L} \frac{\frac{d L}{d_{t}}}{Y}
$$

In equation 1, define $\alpha=\frac{\partial Y}{\partial K} \frac{K}{Y}, \beta=\frac{\partial Y}{\partial L} \frac{L}{Y}$, when $t$ is very small, finite difference can be approximately instead of differential, that is

$$
\frac{\frac{\Delta Y_{t}}{\Delta t}}{Y}=\frac{\frac{\Delta A}{\Delta t}}{A}+\alpha \frac{\frac{\Delta K}{\Delta t}}{K}+\beta \frac{\frac{\Delta L}{\Delta t}}{L}
$$

If $\Delta t=1$, make $y=\frac{\Delta Y}{Y}, k=\frac{\Delta K}{K}, l=\frac{\Delta L}{L}, a=\frac{\Delta A}{A}$

Then the equation turns into

$$
y=a+\alpha k+\beta l
$$

This is the so-called marine economic growth speed equation, among them, $a$ stands for marine science and technology progress speed, $y, k, l$ respectively represent marine GDP, marine fixed assets investment, average annual growth rate of ocean employee population, $\alpha, \beta$ stand for marine fixed assets investment, output elasticity of the ocean employee.

Marine science and technology advance $a=y-\alpha k-\beta l$, namely the ocean science and technology progress means part of output growth that can't be explained by investment increase. That is to say, $\frac{a}{y}=1-\alpha \frac{k}{y}-\beta \frac{l}{y}$, then the contribution rate of marine scientific and technology progress to economic growth can be expressed as $E_{a}=\frac{a}{y} \times 100 \%=\left(1-\alpha \frac{k}{y}-\beta \frac{l}{y}\right) \times 100 \%$, which is also the contribution rate of marine scientific and technology progress we need to calculate.

\subsection{Measurement and Analysis for The Contribution Rate of Marine Science and Technology Progress}

\subsubsection{Estimates Range and Choice of Data}

In the paper, the output data used for the contribution rate of science and technology are national marine GDP, labor data are the total related the employee of coastal areas, and the data caliber is consistent with marine GDP caliber. There are still no statistics for data of marine capital investment, therefore, it is based on the economic data of land region, which corresponds with marine GDP caliber, marine capital investment $=$ fixed asset investment* (marine GDP/GDP), with the measure period of the year of 2001-2010, the specific data for measurement are shown in table 3.

Table 3. 2001-2010 national data for measuring contribution rate of marine science and technology progress

\begin{tabular}{cccc}
\hline Year & $\begin{array}{c}\text { Gross Output Value of Major } \\
\text { Marine Industries (100 million } \\
\text { Yuan) }\end{array}$ & $\begin{array}{c}\text { Employed Personnel in the Major } \\
\text { Marine Industries (10000 }\end{array}$ & $\begin{array}{c}\text { Investment in fixed assets of Marine } \\
\text { Industries (100 million Yuan) }\end{array}$ \\
\hline 2001 & 9518.40 & 2107.60 & 3230.24 \\
2002 & 11270.50 & $/$ & 4074.25 \\
2003 & 11952.30 & $/$ & 4889.82 \\
2004 & 14662.00 & 2780.80 & 6463.29 \\
2005 & 17655.60 & 2960.30 & 8554.60 \\
2006 & 21260.40 & 3151.30 & 11035.14 \\
2007 & 25073.00 & 3218.30 & 13798.44 \\
2008 & 29718.00 & 3270.60 & 16354.69 \\
2009 & 32277.60 & 3350.00 & 21265.61 \\
2010 & 38439.00 & & 26842.02 \\
\hline
\end{tabular}

Data sources: the 2006-2010 China ocean statistical yearbook, 2010 China ocean statistical bulleti. 
Due to the adjustment of 2006 statistical caliber, related employee caliber of coastal areas changes, the employment situation appears to have flaw from the year of 2002 to 2004.

\subsubsection{The Results of Contribution Rate of Marine Science and Technology Progress}

According to the calculation principle of the Solow residual method, marine economy contribution rate of science and technology progress for years of 2001-2010 are measured in this section, the results are shown in the following table.

Table 4. 2001-2010 overall marine economy contribution rate (\%) of science and technology progress

\begin{tabular}{ccccccc}
\hline Year & GDP growth rate & Capital growth & $\begin{array}{c}\text { Capital } \\
\text { contribution rate }\end{array}$ & $\begin{array}{c}\text { Labor growth } \\
\text { rate }\end{array}$ & $\begin{array}{c}\text { Labor } \\
\text { contribution rate }\end{array}$ & $\begin{array}{c}\text { S\&T progress } \\
\text { contribution rate }\end{array}$ \\
\hline $2001-2005$ & 16.70 & 27.57 & 58.94 & 7.18 & 27.66 & 13.40 \\
\hline $2006-2010$ & 16.84 & 25.70 & 54.48 & 3.79 & 14.47 & 31.05 \\
\hline $2001-2010$ & 16.78 & 26.52 & 56.42 & 5.28 & 20.23 & 23.35 \\
\hline
\end{tabular}

\section{Discussion}

From above calculation results we can see, our national marine economy capital contribution rate is $58.94 \%$ for the years of 2001-2005, and the labor contribution rate is $27.66 \%$, contribution rate of ocean science and technology progress is $13.40 \%$. The capital contribution rate of marine economy declines to $54.48, \%$ for the years of 2005-2010, labor contribution rate reduces to $14.47 \%$, research and development of oceans science and technology make huge achievements, contribution rate of marine science and technology progress reaches $31.05 \%$.

The development of ocean science and technology drive our national ocean economy to make the remarkable progress. In the "tenth five-year plan" period, annual average growth rate of national ocean economy is $16.70 \%, 3 \%$ higher than the same period of the national economy, the marine economy becomes a new growth point of national economy. But there are still no obvious changes for problems such as national ocean economic growth mode and marine economic structure optimization during the "tenth five-year plan" period, the contribution rate of marine science and technology is much smaller than that of "eleventh five-year plan" period.

In August of 2008, the state oceanic administration together with the ministry of science and technology issued "The national science and technology plan for developing the sea (2008-2015) ", which required coastal regions to combine with local reality for pushing transformation and industrialization of marine science and technology achievements, that would surely led the ocean science and technology achievements to turn into productive forces better and faster, contribution rate of oceans science and technology progress would be further improved.

National ocean science and technology progress contribution rate is only $23.35 \%$ for the years of 2001-2010, there is still a big gap compared with $70 \%-80 \%$ of the science and technology advance contribution rate of the developed countries, which means we lags behind developed countries for 15 years. Hysteresis of marine science and technology development influence the depth and width of national ocean development directly, thus marine science and technology contribution rate is also much less than the world developed country.

\section{Policy Proposals}

To achieve sustained, stable and efficient development of marine economy, we must rely on the power of technological progress to improve the contribution rate of the marine scientific and technological progress in marine economic growth. Multi-pronged measures of should be taken to promote scientific and technological progress.

\subsection{Accelerating the Development of Marine Economy}

The ocean economy is the backing of the marine scientific and technological development. Only with a strong economic foundation, huge R \& D investment in marine science and technology is guaranteed, marine science and technology can successfully achieve the industrial development and becomes practical productive forces. Accelerating the development of marine economy is the primary task to raise the contribution rate of marine science and technology.

(1) Adjust the emphasis of development and boost optimization and upgrading of marine industrial structure. We should speed up the development of marine industries and transform traditional industries. We must focus on 
building a number of marine industry areas and emerging marine projects that can enhance the overall competitiveness of the marine economy. Meanwhile, we should use the traditional marine technology to update and transform technology which will improve the modernization of the entire marine industry.

(2) Integrate areas of strength and guide the industrial development of marine economy industry. Marine economy should develop in the way of industrialization and large-scale development. China's marine resources are unevenly distributed, poorly configured and the input-output efficiency is not high. We should integrate marine resources to lead marine economy into developing coordinated with land economy, lead coastal provinces (cities) into developing collaboratively, and marine industry developing collaboratively. At present, the integrative cooperation is an important way.

(3) Promote the recycling economy and improve the level of development and utilization of marine resources. Reasonable allocation of the waters of space and marine resources is a good way to promote the marine industry to develop coordinately. Development of marine resources and protection of marine environmental should be planning synchronously and the marine ecological environment should be protected effectively. We should construct a marine eco-environment system with a virtuous cycle, attaches great importance to marine development and protection, take sustainable development of marine economy as long-term development strategy, strengthen comprehensive marine management and construct a good marine ecological environment and resource economic system with a virtuous cycle.

\subsection{Improve Strength of Marine Science and Technology}

(1) The ocean is involved in several industries and covers many fields. The lack of investment in marine science and technology will certainly affect the China's goal of becoming a maritime power. The lack of investment in marine science and technology is one of the main bottlenecks that constrain the marine scientific and technological achievements transferred into practical productive forces. We should increase the financial invest in rejuvenating the ocean through science and technology by a large margin, increase the strength of support for the research of key technologies and core technologies with independent intellectual property. Departments at all levels should support the marine high-tech enterprises and marine research institutes and improve R \& D capabilities. R \& D expenditures are tilted to the marine science and technology. All Provinces (cities) should actively guide the marine small and medium-sized enterprise to increase their scientific and technological input, to get rapid growth and enrich the strength of marine scientific and research, improve the investment structure of the marine science and technology.

(2) Cultivate and accumulate marine human resources. We should increase the cultivation of marine professionals in regional colleges and universities as reserve of talents, attach great importance to the growth of personals in marine scientific research institutions, train young researchers by marine scientific research and subjects, train a group of marine science and technology disciplines to take the lead as a strategic task to improve the overall quality of personals of the marine science and technology, focus on training and bringing up talents who can enter the forefront of marine science with international influence, have a plan to select professionals on marine science and technology to study abroad to learn and build a streamlined, efficient, innovative personnel of marine science and technology.

\subsection{Speed up Transformation of Scientific and Technological Achievements}

Only translated into practical productive forces and by the promotion of market, marine scientific and technological achievements can achieve its economic effects. Establishment of bases of marine high-tech achievements transformation is a good form to promote integration of technology and economy and the main carrier of transformation of marine science and technology. Coastal provinces and cities should centralize certain financial and technical strength, establish of several paradigmatic marine hi-tech parks, attract enterprises and sectors of science and technology to enter the parks by policies and economic instruments and drive the development of high-tech industries in marine areas to promote marine economy grow rolling rapidly.

Strengthening construction of service system for industrialization of marine science and technology and the establishing teams for promotion of marine science and technology is also an important part of transforming marine science and technology achievements. Governments should set up specialized agencies to promote science and technology promotion program to promote advanced and applicable technologies, construct promotion team of marine science and technology and speed up the popularization and application of advanced and applicable marine scientific and technological achievements through experiment, demonstration, training, guidance, and consulting services to. We should cultivate a variety of intermediary organizations providing technology services, such as the foundation of the Engineering Technology Center, technical advice and high-tech information network to provide technical identification, screening, assessment and consulting services, 
gradually forming marine science and technology service systems providing the whole process service including research, development and promotion.

\subsection{Increase Government's Support}

Government's efforts to support marine science and technology are very important to improve the contribution rate of the marine scientific and technological progress. Marine enterprises have not been truly become the main players in the market and the proportion of invest in marine technical is still small. The main body of China's marine science and technology R \& D is still the Government and marine research institutions with government's support, which is related to the direction and focus of development of marine science and technology. The government is the main investor of invest in marine science and technology and government's support is very important when raising the contribution rate of marine technological progress.

The government should provide support on funding, tax incentives, science and technology collaboration to promote marine economic structure adjustment and industrial upgrading and speed up the process of industrialization of marine science and technology. The government should strengthen investment in the development of technology, especially the marine basic research. The government should improve the mechanism of marine science and technology development to create a favorable external environment for enterprises' technological progress and to create a good foundation for enterprises' technology development. In addition, the government should also provide appropriate tax incentives to enterprises of marine high-tech industries to encourage enterprises to conduct marine scientific and technological innovation, for the purpose of the formation of a good social atmosphere for the marine scientific and technological innovation.

\section{Acknowledgements}

This paper is supported by the project of National Social Science Fund "Monitor and Early-Warning Research on China Marine Economic Periodic Fluctuation"(11AJY003)and National Marine commonweal industry scientific research fund "Marine economy monitoring and assessment technology and the typical regional demonstration research" (200805081).

\section{References}

Charnes, A., Cooper, W., \& Golang, B. (1985). Foundations of data envelopment analysis for Pareto-Koopmans efficient empirical Production Functions. Journal of Econometrics, 6, 45-62. http://dx.doi.org/10.1016/0304-4076(85)90133-2

Cheng, D. (2006). The Evaluation of Sustainable Development based on Ecological Footprint and Human Development Index--A Case of Marine Fishery Resources Utilization in China, China Soft Science, vol.18, pp.27-40. http://mall.cnki.net/magazine/Article/ZGRKX200605018.htm

Coe, D., \& Helpman, E. (1995). International R\&D spillovers. European Economic Review, 39, 26-42. http://dx.doi.org/10.1016/0014-2921(94)00100-E

Denison, E. (1985). Trends in American Economic Growth, 1929-1982. Washington D.C.: The Brookings Institution.

Feng, Y., \& Li, C. (1992). An expression of production function and measurement of the relative benefits. The $\begin{array}{llll}\text { Journal of Quantitative \& Technical Economics, } & \text { 9, }\end{array}$ http://mall.cnki.net/magazine/Article/SLJY199209067.htm

Feng, Y., \& Li, C. (1999). Analysis and Reconstruction of science progress measurement method. China Soft Science, 9, 85-92. http://d.g.wanfangdata.com.cn/Periodical_zgrkx199909008.aspx

Griliches, Z. (1986). Productivity R\&D and basic research at the firm level in the 1970's. American Economic Review, 76, 141-154. http://www.jstor.org/stable/1804132

Jan, T. (1939). Business Cycles in the United States, 1919-1932. League of nations, Economic intelligence service, 7, 69-56. http://www.jstor.org/stable/1807628

Liu, X., Li, X., \& Cao, H. (2004). Pilot evaluation of China's marine science and technology industry. Science of Science and Management of S\&T, 11, 86-92. http://mall.cnki.net/magazine/Article/KXXG200411023.htm

Qiao, J. (2010). The Analysis of Marine Technological Innovation on the Basis of Marine Industry Structure $\begin{array}{llll}\text { Optimization in China. Reformation \& } & \text { Strategy, } & 10,\end{array}$ http://mall.cnki.net/magazine/article/GGZY201010046.htm

Shi, Q., \& Qin, B. (1985). Technology progress and economic growth. Beijing: Science and technology literature press. 
Solow, R. (1956). A contribution to the theory of economic growth. The Quarterly Journal of Economics, 17, 69-89.

Swan, Trevor W. (1956). Economic growth and capital accumulation. Economic Record, 11, 52-65. http://dx.doi.org/10.1111/j.1475-4932.1956.tb00434.x

Wang, T. (2003). The measurement of contribution rate of scientific and technological progress in China's economic growth. Productivity $\quad$ Research, $39-48$. http://mall.cnki.net/magazine/Article/SCLY200309010.htm

Wu, Y., \& Shi, P. (2006), Evaluation and Analysis of the Competitiveness of Marine Science and Technology of Coastal Regions of China. Shanghai Economic Review, 2, 79-85.

Ye, X. (2006). Allocation of scientific resources and the development of China's marine economy. Ocean $\begin{array}{llll}\text { Development } \quad \text { Management, } & \text { 61-65. }\end{array}$ http://d.g.wanfangdata.com.cn/Periodical_hykfygl200902021.aspx

Yu, J. (2009). Research on contribution rate of scientific and technological progress in China. Soft Science, 25, 46-58. http://mall.cnki.net/magazine/Article/RKX200925046.htm

Zhao, D. (1998). The measurement of the human resource contribution. Economic Science, 25, 55-60.

Zhou, S., \& Hu, D. (2010). Research on Contribution Rate of Science and Technology Progress to Economy Growth. China Soft Science, 2, 65-82. http://d.g.wanfangdata.com.cn/Periodical_zgrkx201002010.aspx 